\title{
TITLE: VISAR: LINE-IMAGING INTERFEROMETER
}

author(s): W. F. Hemsing, A. R. Mathews, R. H. Warnes,

M. J. George, G. R. Whittemore

suemitreo ro: 1991 American Physical Society Topical Conference Williamsburg, $V A$

June $17-21,1991$

\section{Disclaimer}

\begin{abstract}
This report wes prepared as an eccount of work sponeorod by an agency of the Uniled stalate Government. Neither the Uniled Siates Covernment nos any agency thereof, nor any of their omployees, makes any warranty, exprese of implled, or awumes any legal liability of responaibility for the accuracy, cumptetenese, of ucofulneas of any information, apparatus, product, of process disclued, or represents that its use would not infringe privately owned ridhto. Reforence herein to any specifle commerciul product, procen, or ervice by irade name. Irademart, manufacturer, of otherwise does not neceauarily consutitute of imply its endorsement, recommendution, of fevoring by the Unitod Stutes (jovernment of any agency thereof. The viows and opinions of authons oxpreaced herein do not neceasurily atale or reflect thuse of the Uniled Sitalea (fovernment or eny agency thereof.
\end{abstract}

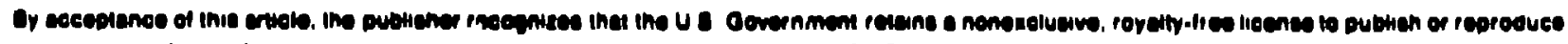

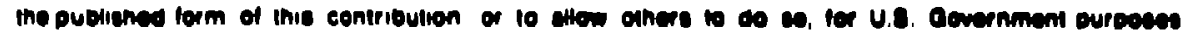


VISAR: LINE-IMAGING INTERFEROMETER

\title{
V. F. HEMSING, A. R. MATHEWS, R. H. WARNES, M. J. GEORGE AND G. R. WHITTEMORE $\dagger$
}

Los Alamos National Laboratory, Los Alamos. New Mexico 87544

\begin{abstract}
A line-imuging Velocity Interferometer System for Any Reflector (VISAR) was applied to measure velocity across the diameter of a metel plate explosively accelented to $5.5 \mathrm{~km} / \mathrm{s}$. Amplified, single-frequency laser light was focused to illuminate a line on the metal surfece. The line's image was focused through the inierferometer to a streak camera that swept in time and reconded directly on film. During the experiment, the Doppler-shift caused motion of the interferen $x$ fringes. Amlyais of the digidzed flm record yielded a conrinuum of time-resolved velocity histories. Velocity gradients actoss the plate that first swept ndially inward, then reflected nutward, were clearly mensured. Increased power provided by the laser amplifier greatly improved the signal-to-noise ratio compared to our previous line VISAR expeninients.
\end{abstract}

\section{INTRODUCTION}

A line-imagling Velocity Iniefferometer System for Any Reflector (VISAR) 1,2 wa demonstruted last year with a 2-W, single-frequency, aron-ion hser to messure many velocity hiscortos simuluneously. However, an image Intensffer was required and the resulting signal-to-noise ndo was poor because of the marginal laser power.

An umplifie-3,4 was recently inatalled to boou laser power to approximately $600 \mathrm{~W}$. It eltminated the requirement for in imioe Intens'fler, allowing an increase from 40- 10 the full 63-mm-dlam camen Image, and greatly impuived the algnalw-noter rato. This enabied velocit; measurements to be made scross the diameter of an explonively driven plate over - 10-m optcal path berween tho experiment and the VISAR. During the experiment, the 2-mm-thick, 25-mm-diam 304 uninleas oteel plate was unevenly sccelerated to a velocity of $5.5 \mathrm{~km} / \mathrm{h} \ln 4 \mu \mathrm{s}$. The plate, inlially in an evacuated barrel capped by an optkal window, wes follo 'wed to a dierance of $15 \mathrm{~mm}$ before the optlcal path becumo obucured by smoke from the exploutve driver. Simultaneous differences in veloclty, creater than $0.5 \mathrm{~km} / \mathrm{s}$, wero measured between center and adge regions ccross the plate.

Thls paper begins with a disyrem to lllustrus the exper. imental syatem. Itu operadion bs explained. Then ecyulation and andyuls of the experimental urrenk cumera photojnaph with it four imuges is described, utaning from the raw Image and concluding with velactly hlutories.

\section{EXPERIMENTAL SETUP}

Figure 1 Ulustrates the experiment. Light from a singlefrequency, argon-ion laser was amplified from I to $6100 \mathrm{~W}$ by a dye-laser amplifier. Its output was focused by a cy.unJrical lens to illuminate a line $25-\mathrm{mm}$ long on a lighily sanded region across the plate, to be lnunched in vacuum. A sphisical lens collected diffusely reflected light from the plute and focuscd it thiough the VISAR interferometer.

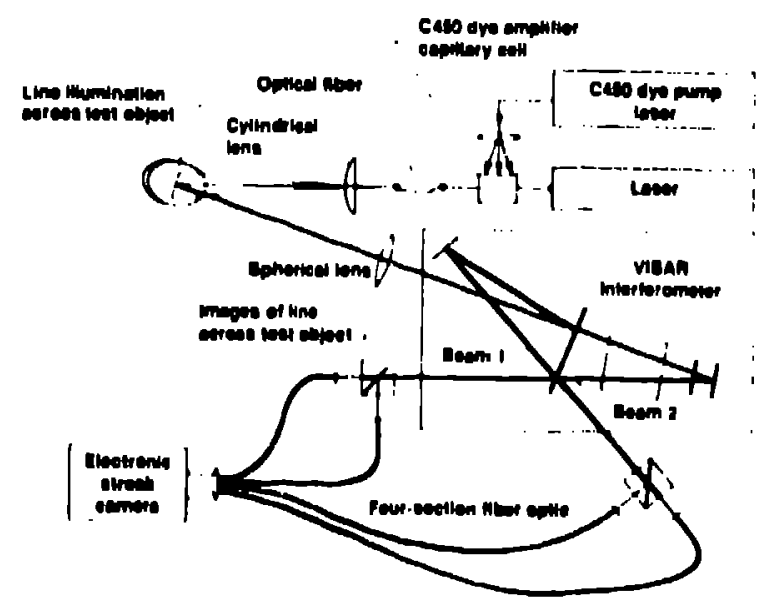

MOURE 1

Line-lmaging VISAR experiment. opherical lens collected diffusely reflected lighi from the plute and fix'uned it thriugh the VISAR interferomein.

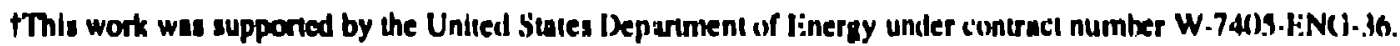


Light traversing the interferometer was split into two beams: one was slowed by transmission through a $100-\mathrm{mm}$ long glass bar and an eighth-wave retardation plate while the other taveled through air. This provided a relative delay yet gave identical magnifications in both interferometer legs. The delay made the interferometer sensitive to acceleration; the retardation plate provided quadrature codings. After being recombined, the light was output from both sides of the teamsplitter, in "push-pull" mode, to maximize light efficiency and minimize nuise.

Polarizing splitters separated the push-pull beams into four quadrature-coded components with $90^{\circ}$ relative phase differences. The beams then formed images at the focal plane of the spherical lens on the entrances to fiber optic bundles for transmission to the streak camera.

Each bundle was aligned individually tw ensure good focus and equalize magnifications so thet corresponding points in all quadrature images would map to a single point on the plate surface. Overall magnification was adjusted for the images of the illuminated line to fill the $0.2 \cdot \mathrm{mm}$. wide by 6-mm-long fiber ontic bundles. At their exit ends, the bundles were combined side-by-side into a 0.2 - by $24-\mathrm{mm}$ linear array placed in direct contact with the streak camera fiber optic phs:ccathode window.

\section{DATA ACQUISITTON AND ANALYSIS METTIOD}

\subsection{Data acquisition}

Acceleration of he plate during the experiment produced a Doppler-shift of the ligh: This caused interference to nodulate the quadrulure inages when they were swept actoss recording film by the electronic streak camera. The resulting time-resolved photograph was later di, titized by a microdensitemeter and stored on computer disk for analysis.

3.2 Approach to duta analysis

The streak record was digitized with approximately 500 pixels nlong the time coxordinate and $4(X)$ pixels across the spatial coordinute. Four $S(X)$ by $I(X)$ pixel quadrature images were cut from it and registered to each other. The digitized Ilm density data were expxonentiated to approx:mate light intensity. Then the $180^{\circ}$ quadmeture image was subtracied from the ( $)$ image to obtain a sine image, and the $27(0)$ inage war subaracial from the $x$ r image to give a covine inage.

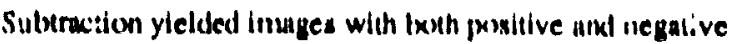

values, canceled common optical noise and improved the signal-to-noise ratio.

A pointing device was used to manually trace the interference fringes on a computer display of the difference images. Each fringe was assigned a number, counting from zero at the beginning of the record. Velocity was calculated by multiplying the fringe count at all points in each trace by the fringe constant of $411 \mathrm{~m} / \mathrm{s} /$ fringe. No acceleration reversals were observed sr counted. Velocities for times tetween traced fringes were estinlated using interpolation.

A previously developed anctangent algorithm that calcuiates velocity semiautomatically from the sine and cosine images was not used for this analysis because of imperfections in the photograph and because sufficient ditt: ivere easily traced. Software tcols are being developed to use pre-experiment, static photographs to account for interferometer and optical imperfections

\section{STREAK PHOTOGRAPH IMAGE ANALYSIS}

\section{I Line VISAR quadrature streak image}

The microdensitometer-digitized streak photograph is shown in Fig. 2. Note th: $90^{\circ}$ relative phase differences between interterence fringes visible in the four quadrature images. The optical fiber bundles were oriented so that the images were reversed about the streak-tube centerline to minimize effects of distorion. Before further analysis, each quadrature image had to be separated from the gmup. reversed if necessary, and registered with the other images.

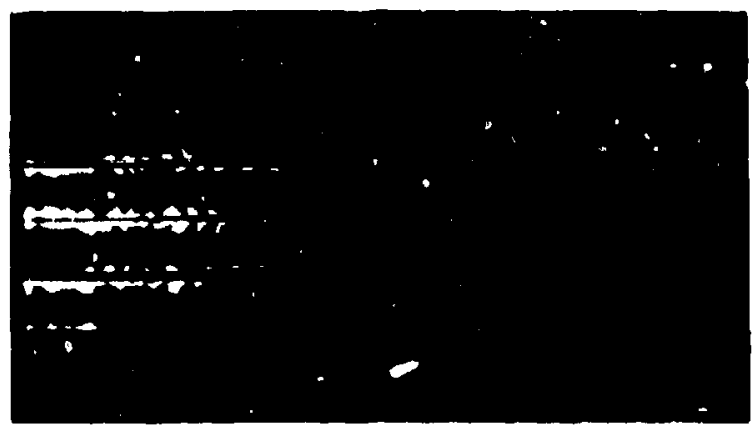

FIOJJRE 2

Microdensitometer image from the streak cannera photograph of four quadralure ima ies. Time nurk interval is $0.3 \mu \mathrm{s}$, increasing to the right. Position along thr 'ine on the metal surfinic is represented by the vertica! coxurdinale. 
4.2 Push-pull difference images

The film density data were exponentiated to convert them to approximate light intensity. Figure 3 shows the difference inages obtained by subtracting the (-sine) image from the sine image and the $(-\operatorname{cosine})$ image from the cosine image.

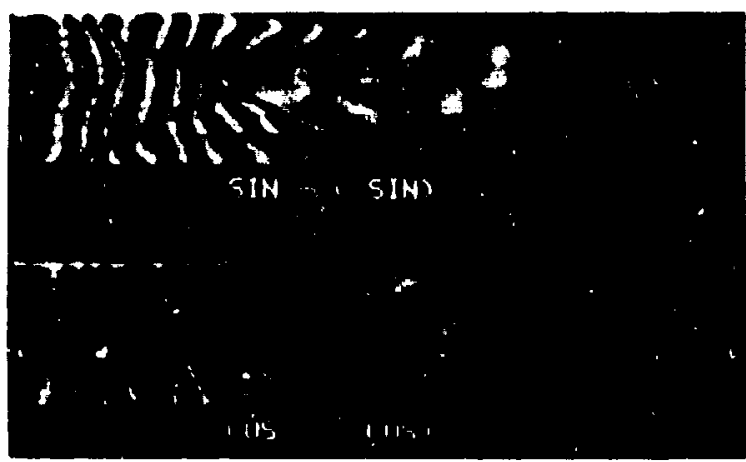

FIGURE 3

Sine and cosine difference images.

4.3 Intensity image: sum of four quadrature images

Figure 4 shows the sum of all four quadrature images that provides a time vs position history of the total lighe returned from the turget. This image is useful to indicate correct registration between all four quadrature images. When properly registered, there should be no interference information visible in the sum image. Imperfect registration is applincrit to the upper left where fringes are slightly visible. I daser intensity variations are also visible, especially near the right end. Dark reginns have insufficient light for anulysis.

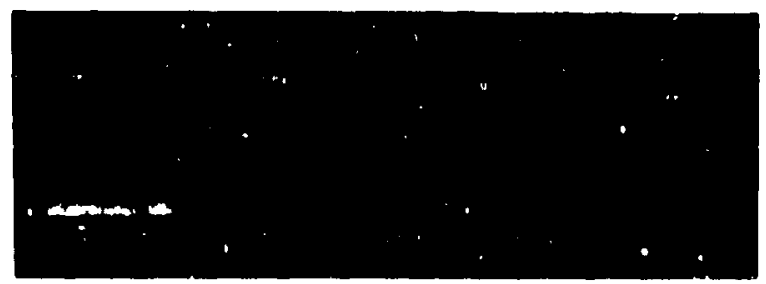

FICIURE 4

Iniensily image: sum of four quadralure litages

\section{FRINOE COUNI' ANI) VIILOXTTY (AI.CUIAIION}

\section{S.I Fringe tracing}

Individual bright and dark interference fringes wers: munually inced from both the sine nud cosine difference images. Each trace was numbered starting at zero before the start-of-motion. The traced points are plotted in Fig. 5.

FIGURE 5

Manually traced points on fringes from difference images.

\section{S.2 Relationship between velocity and fringe count}

Velocity was calculated for each traced point by multiplying its interference fringe count by $411 \mathrm{n} / \mathrm{s}$. This left gaps in veloxity data between tracings.

5.3 Veloxity plots and interpolation

A simplex interpolation algorithm was then used to estimate velocity between the traced points. It yielled a continuous velocity history across the metal plate over the time of the experiment. Results are plotted in Iig. 6.

Visible in Figss. 2,3,5 and 6 is a triangular region

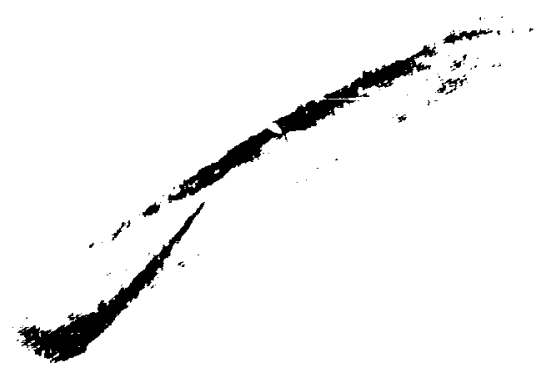

litolite? o

Isometric plot showing velexity as of function of time and

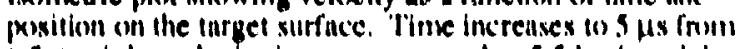
left 10 -right, velocliy increases upward $10.9 .9 \mathrm{~km} / \mathrm{s}$ and the iksition along the plate extends to $25 \mathrm{~mm}$ up atul to the left 
bordered by the star of the record on the left and by abrupt changes in fringe position, produced by corresponding plate acceleration, on the right. The abrupt acceleration resulted from a radialy converging stress wave, or shock, in the explosive driver that first fi:opagated inward to the center axis and later reflected ouliward.

Datu from several discrete imes in Fig. 6 are reploned in Fig. 7 to emphasize the large velocity differences that existed across the plate during its acceleration. Interestingly, at 1.5 $\mu$ s the velocity difference exceeds $0.5 \mathrm{~km} / \mathrm{s}$.

\section{S.4 Displacement ploxs}

Displacement information was calculated by integrating

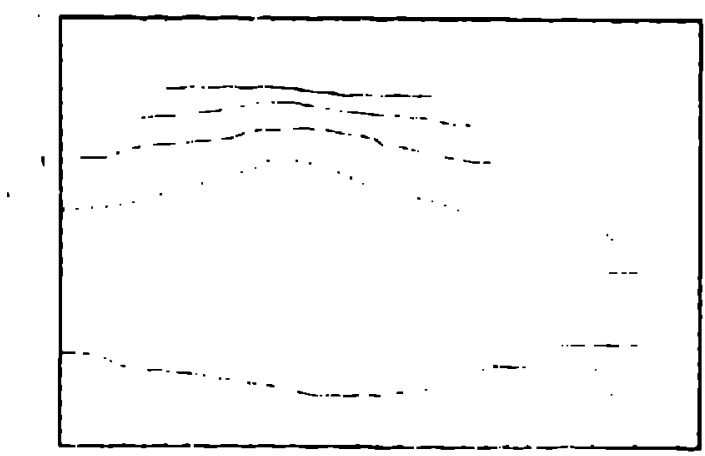

FGURE 7

Veloctiy vs position actoss the plate at several discrete itmet during the experiment.

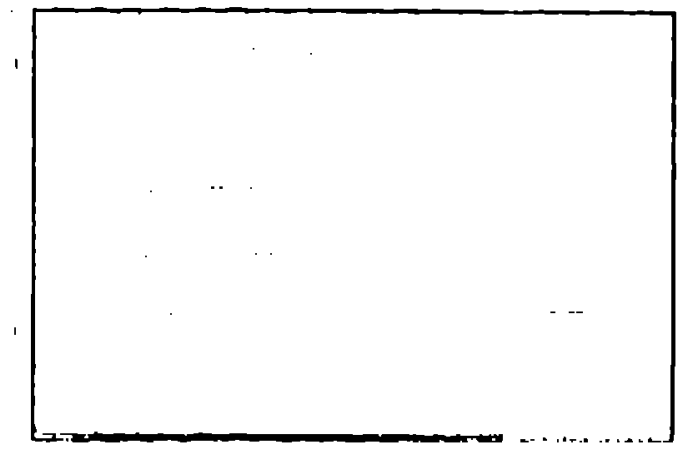

IACIURE :

Dlaplacement vs panition acrous the plate at several discrete Umes during the experiment. the velocity data with respect to time. Curves plotied in Fig. 8 represent the physical shape of the illununated line on the plate at several discrete times during the experiment. Nole the change from concave to convex. By comparing Fig. 8 to Fig. 7, it can be seen that subtle changes in shape mask the large differences in velocity that existed across the plate.

\section{CONCLUSION}

A dye amplifier has provided $600-\mathrm{W}$ single-frequency power starting from an argon-ion laser. The increased power enabled imaging velocity measurements over a $10 \mathrm{~m}$ optical path. greatly improved the signal-to-noise ratio and eliminated the requirement for an image intensifier.

The capability to sense acceleration was especially useful in this experiment. Strong velocity pertubations that swept inward and later reflected ounward were measured as the plate accelerated to $5.5 \mathrm{~km} / \mathrm{s}$ in $4 \mu \mathrm{s}$. The existance, structure and $>0.5 \mathrm{~km} / \mathrm{s}$ magnitudes cf the velocity differences that existed simulenneously were clearly messured in a single experiment by the line-imaging VISAR but might have been masked by sho-to-shot variations in many, separate, single-point velocily experiments.

\section{REFERENCES}

1. L. M. Burker and R. E. Hlollenbach. "Laser Interferometer for measuring high velocities of any reflecting surface," J. Appl. Phys., Vol. 43, No. 11. pp 466(9-467. 1972.

2. W. F. Hemsing et al. "VISAR: L.ine-Imaging interferometer," Ultrahigh- and High-Speed Photography. Videography, Photonics and Velocimetry, Shaw, Jaenimapi. Neyer, Editon. Proc. SPIE 1346, pp 133-140, (1990).

3. L. L. Steinme!z, "New Laver Amplifier Improves Laser Doppler incerferometry," Eneroy and Technology Revlew (UCRL-52000-86-2), PP 1.7 .

4. Cardela Lauer Corporetion, leser amplifier for las Alamos Nallona Laburatory. 1990.

5. O. M. B. Bourtcius and S. F. C.lifrord," An (roplical Interferometer Using Polarizalion Coding fo ()tyain Guadrature Phase Components." Kev. Sci. Instrum. (41) PP IR(D) 18(13), 1970). 